\title{
The Approaches of Teaching Reform in Universities in Audit Assessment
}

\author{
Rong-xiang Guo \\ Office of Academic Affairs \\ Nantong University, Nantong \\ Nantong, 226019, China \\ guo.rx@ntu.edu.cn
}

\author{
Hui $\mathrm{Xu}^{*}$ \\ School of Computer Sci. \& Tech \\ Nantong University \\ Nantong, 226019, China \\ *Corresponding author: xu.h@ntu.edu.cn
}

\begin{abstract}
Audit assessment is a new measure to adapt to the development of higher education, a new requirement that makes people satisfied with higher education, and a new requirement for realizing the medium and long-term development goals of the country. This paper discusses the ways in which teaching reforms can be applied in the audit assessment: strengthening consciousness of quality education, implementing quality connotation construction, innovating talent training model, optimizing the structure of undergraduate majors, focusing on the construction of curriculum resources, improving the construction of specialties, students' innovation awareness and practical ability, strengthening process management, and improving the quality assurance system. Only by continuously exploring and "combination evaluation with construction", universities can win the first chance in the audit assessment and the development of higher education.
\end{abstract}

Keywords-Audit assessment; Universities; Teaching reform; Approach

\section{INTRODUCTION}

The fundamental purpose of audit assessment is to promote the establishment of colleges and universities personnel training center position and establish a scientific concept of higher education development; adhere to a stable scale, optimize the structure, strengthen the characteristics and pay more attention to innovation; encourage colleges and universities shift the emphasis from the extension of the construction such as vestment and scale to quality and structure of connotation construction; vigorously carry out education and teaching reform, take the characterized road of the quality improvement as the core of the connotation development.

\section{THE SIGNIFICANCE OF THE AUdit AsSESSMENT}

Under the new situation of higher education in our country, summarize existing assessment experience, the audit assessment has been put forward as a new assessment model based on foreign advanced assessment thought. The core of the work is to evaluate the achievement of school personnel training objectives and training effects, promote the diversification of personnel training, emphasize respect for the autonomy of school running, and reflect the school's dominant position in the quality of personnel training.

\section{A. It is a New Measure to Adapt to the Development of Higher Education}

Higher education enters to the popular education stage from the elite education stage, whether the mode of running a school, the school system, and form of running a school, or the values, the quality concept and the policy orientation all have diversified. Social change affects the development of higher education, and higher education must take the initiative to adapt to social changes. At present, the Chinese society as a whole has gone from "diploma shortage" to "diploma relative surplus" era. The value of higher education is changing from "providing high diploma diploma" to "providing education that meets the needs of students", from providing employment to providing education and from cultivating talents to helping talent growth.

The guiding ideology of audit assessment is "one persistence, two prominences and three strengthening" [1]. "One Persistence" refers to follow the principle of" promoting the construction with evaluation, promoting the reform with evaluation, promoting the reform with assessment, combining assessment with construction, emphasis on construction ", guided by the spirit of the 19th CPC National Congress and the national educational plan. " Two prominent" is to highlight the connotation construction, highlighting the distinctive development. "Three strengthening" means strengthening the reasonable positioning of running a school, strengthening the center of personnel training and strengthening the construction of quality assurance system.

\section{B. It is New Demands of Higher Education Satisfied by People}

The current situation of higher education in our country is "big but not strong". Although the world's largest system of higher education has been established, a good institutional environment that matches the changes of higher education's functions and objectives has not yet been established. The transformation and reform of the higher education system that is compatible with the transition from the elite stage to the popular stage of higher education has not yet been completed. Therefore, how to solve the problem of raising the quality of higher education, providing more quality higher education resources and better services for the broad masses of the people 
and fulfilling people's satisfaction with higher education has become the core task of higher education reform.

The essence of audit assessment is three important "guide" [2]. That is to guide colleges and universities to update their educational concepts, adhere to the student-centered, focus their efforts on personnel training and teaching; guide colleges and universities to deepen the reform of education and teaching, do their own characteristics, form advantages and diversify their development; respect the autonomy of running a university and strengthen the dominant position of the construction and monitoring of the quality of colleges and universities, arouse the initiative and creativity of college personnel training.

\section{It is a New Requirement for Realizing the Medium and Long-term Development Goals of the Country}

The essence of the audit assessment can be summarized as "four degrees of conformity." First, the fitness degree of the positioning of school running, personnel training objectives and national and regional economic and social development needs; second, the guarantee of teachers and teaching resources third, the effectiveness of the teaching and quality assurance system; fourth, satisfaction of students and social units.

The purpose of the audit assessment is to guide colleges and universities to locate their own schools, set suitable personnel training objectives and the corresponding quality standards, deepen reform of the personnel training mode and teaching, and cultivate high-quality personnel that meet the needs of national and local economic and social development. The focus of the audit is through what kind of quality assurance system of colleges and universities to achieve their own goals of personnel training? How to achieve the goal? How is the effectiveness and reliability of the school's internal quality assurance mechanism? As well as the reform and construction measures and policies are taken to achieve the quality standards.

\section{THE EFFECT OF AUdIT ASSESSMENT ON TEACHING REFORM IN UNIVERSITIES}

Since the assessment was conducted, all colleges and universities aim to improve education teaching quality, strengthen connotation construction, Strengthen the connotation construction, Strengthen the central position of teaching work, Constantly deepen the teaching research and reform, promote teaching quality and teaching reform project with high starting point, high level, and high quality, Reform innovative talent training mode, continuously improve education teaching quality [3].

1) Strengthen the consciousness of quality standing school, firm the position of teaching work center. The quality of personnel training is the lifeline of the development of colleges and universities and the key to realizing the strategic goal of building a strong country for human resources and an innovative nation. All participating colleges and universities have always put undergraduate teaching as the center of the school work, personnel training as the fundamental mission, change the concept of education as the guide, practice, teaching reform with modern education, talent view and quality, deepen the teaching reform and improve the quality of teaching to the letter. The structure of expenditure is adjusted actively, investment in teaching is increased, teaching is strengthen with more energy, greater financial resources.

2) Implement construction of quality connotation, Promote teaching reform and development. All participating colleges and universities adhere to the quality of personnel training as the main measure of school-level standards, adhere to the people-oriented, closely around the optimization of the structure and layout, reform training mode, innovate system and mechanism, improve the quality assurance system to deepen education and teaching reform and raise the level of personnel training.

Many colleges and universities take quality construction projects as their starting point and take active measures to build a three-level quality engineering system at national, provincial and school levels to give play to the demonstration and leading role of quality construction projects, encourage teachers to conduct in-depth teaching and research, actively explore the construction of curriculum resources, and constantly increase and update the knowledge accumulation, improve teaching ability and level, and effectively improve the quality and effectiveness of teaching.

3) Innovative training model, the formation of a wide range of personnel training pattern. Many participating colleges and universities actively explore and innovate multistandard, multi-level and individualized personnel training mode; establish a new mechanism for joint training of talents by universities and industrial enterprises, and promote the teaching reform and innovation programs of excellent engineers, excellent doctors, excellent teachers and undergraduate personnel training models in an organized and planned manner[4]; explore new ways of personnel training mode, strengthen international cooperation in running schools, continue to expand cooperation with overseas universities, carry out exchanges and visits with students from overseas high-level universities and mutual recognition of credit, carry out friendly exchanges with overseas universities and units and expand cooperation the depth and breadth of running a school.

4) Optimize undergraduate professional structure, improve the professional construction level. Colleges and universities adapt to the development of economic and social development and the development of disciplines, and actively integrate into local economic and social development, continue to adjust and optimize the undergraduate professional structure in connection with local economic and social advantage industries and pillar industries, and meet the demand for talents in local economic and social development, construct the professional structure of the disciplines and the coordinated development of undergraduate majors, To carry out the construction of key professional (class) based on the same or similar principles, promote the comprehensive reform of the important links that affect the undergraduate professional development such as training mode, teaching team, course materials, teaching methods and teaching management, professional education has been steadily improved. 


\section{THE EFFORTS DIRECTION OF UNIVERSITY TEACHING REFORM IN THE AUDIT ASSESSMENT}

"Personnel training model" refers to the process of implementing talent education with relatively stable teaching content and curriculum system, management system, and assessment method under the guidance of certain modern education theories and educational thoughts, according to specific training objectives and talent specifications [5]. Specifically, it includes training objectives and specifications, a whole set of education processes for realizing certain training objectives and specifications, and a set of management and evaluation systems for achieving this process, matching scientific teaching methods, methods, and means. Audit assessment is the means, the purpose is to improve the quality of undergraduate education. In the coming years, it will be a crucial period for China's higher education to achieve its transformation and development, its connotation development, and its distinctive development. We need to review the situation and grasp the great opportunity of the connotationoriented development. We should make plans from a high starting point and push forward with a high standard to achieve a new leap forward in undergraduate teaching.

1) Constantly explore and reform undergraduate talents training mode. Universities should speed up the diversification of personnel training mode, carry out the reform of academictype personnel training as the goal of training various types of innovative talents based on the doctorate-authorized subjects and dominant disciplines and on the basis of the cultivation of applied talents. A scientific, reasonable and feasible training framework for personnel is built from scientific disciplines, training programs, faculty, student management, experimental conditions, teaching reform, practical teaching and other aspects. We should deepen the reform of the training model of applied talents, try the reform of the mode of joint training of school-enterprise closely in the form of embedded service and service outsourcing, and push forward the implementation of the excellence plan in an all-round way.

2) Enhancing the connotation and further promote professional comprehensive reform. Key specialties refer to a certain school's professional objectives in terms of educational goals, teaching staff, curriculum system, teaching conditions, and training quality. It has a relatively high level of education and distinctive characteristics of running schools, which has produced better educational benefit and social impact. It is a high standard, high level, high quality professional [6]. Universities should focus on strengthening undergraduate construction; continue to promote undergraduate teaching projects; integrate disciplines, specialties, curricula and teams; implement comprehensive professional reform and innovate personnel training mode; strengthen the construction of teaching team, curriculum system and teaching materials; and constantly reform teaching Methods and means. Professional certification is carried out in batches. We should combine professional comprehensive reform, key professional construction and professional certification, combine the audit assessment with professional certification, effectively enhance the content of professional construction, improve the level and quality of professional construction.
3) Both knowledge and practice, focusing on teaching resources construction. Universities should manage the curriculum construction project hierarchically according to the foundation of existing curriculum and the current situation of teaching reform [7]. It is necessary to increase funding for key construction projects such as MOOCs, quality resource sharing courses, quality video open courses, micro-curricula and bilingual courses, introduce competition mechanisms and improve the level and requirements of curriculum resources. We should encourage teachers to innovate teaching methods and means, take the initiative to adapt to the international trend of teaching reform, to explore new teaching modes such as online learning, mixed learning and overturning classrooms; strengthen the training guidance of students' learning strategies and methods, to cultivate students' self-discipline and critical thinking. Experimental teaching is overall optimized, experimental teaching methods and means are innovated, quality education in an all-round way is promoted, and talents generally welcome by social and employers are cultivated with comprehensive high quality, practical ability.

4) Building a platform to cultivate students' innovative spirit and practical ability. The university should strengthen the laboratory construction, constantly improve the laboratory hardware and software conditions. The university should straighten out the laboratory management system, improve laboratory management rules and regulations, integrate resources, establish management mode integrated teaching and research laboratories, develop the laboratory to large-scale, standardized, efficient and open, and constantly improve the comprehensive laboratory efficiency and management level. Through scientific positioning, creating quasi-enterprise production training platform, better serve the cultivation of professionals, service teaching reform in practice, to serve students 'innovative training, and to serve students' entrepreneurship education. Through the introduction, training and part-time, engineering training instructor team and technical support staff are built with reasonable structure consisted by engineering background, education, age, and professional title, with multi-disciplinary integration, multifield engineering and technical personnel support, and being involved by multi-management. It is necessary to strengthen the overall co-ordination and coordination of practice (experiment) teaching and theoretical teaching, strengthen the construction of practice bases, promote the implementation of practice training programs for undergraduates, and strive to cultivate and enhance the practical ability, innovative spirit and sense of social responsibility of undergraduates.

5) Increase efforts to speed up the construction of teachers. Without qualified teachers, education can't be further developed. To establish the concept of talent is the first resource, work hard at the "introduction, education, management, evaluation" [8]. The introduction is to introduce the domestic and foreign high-end talents. It is necessary to study new ways and means of attracting high-level talent so that top talent and urgently needed talents can be attracted, retained and used well. Education is to focus on cultivating young teachers. We should take cultivating young talents as an important task in building a contingent of teachers, give more support to the growth of young teachers, and give more 
opportunities to break down all kinds of obstacles that hinder the growth of young talents and display their talent, and use young talents eclectically. Management is to deepen the reform of the personnel management system. It is necessary to improve the job management system, optimize the structure of professional and technical personnel standards, rationalize the employment relationship, invigorate the employment mechanism, improve employment efficiency, maximize the enthusiasm and creativity of the majority of teachers. Evaluation is to speed up the construction of scientific and rational teacher evaluation system. It is necessary to implement teacher ethics as the primary content of performance appraisal and reward and the implementation of ethics is one vote veto system. Exploring teachers' classification and evaluation methods to form a teacher evaluation mechanism based on performance contribution and ability level.

\section{CONCLUSION}

Improving the quality is the key word of the appraisal, is the main theme of higher education reform, is the core task of the development of higher education and the basic requirement of building a strong country with higher education. As the basis of the university, undergraduate teaching undertakes the mission of cultivating the talents with the largest number, the most extensive tasks and the most arduous tasks, which has a crucial impact on the educational level and core competitiveness of colleges and universities. Therefore, colleges and universities should take the construction of highlevel undergraduate education as a starting point, take cultivating high-quality practical talents as a focal point, take the solution to the difficulties and problems in undergraduate education and teaching process as a breakthrough point. We will boldly innovate and constantly open up, deepen the reform of education and teaching in an all-round way, continuously improve the quality of personnel training, successfully complete the development goals of the "Outline of the National Medium and Long-term Education Reform and Development Plan."

\section{REFERENCES}

[1] J.K.Dong, Y. Han, Z.X. Liang, "Interpretation of the view of the ministry of education on the evaluation of undergraduate teaching," Higher Education Development and Evaluation,Vol. 29, pp.12-18, May 2013.(In Chinese)

[2] H.B. Li, Y. C. Xing," Grasp the core of the spirit of science, implement the audit assessment," China Higher Education ,pp.31-33, Jun. 2014. (In Chinese)

[3] H. L. Liu, "Sudy on the validity of undergraduate teaching auditing evaluation," Journal of Jiangxi Social Sciences, pp.236-241, Apl. 2014. (In Chinese)

[4] D, H. LIN, "Audit evaluation: development context,present situation analysis and future prospect- A research based on fifty-one universities", Modern Education Science,pp.1-7, Sept. 2016. (In Chinese)

[5] A.F. ZHANG,"Rational knowledge of several problems about the quality audit of under- graduate teaching," Higher Education Development and Evaluation, pp.1-7,Jan,2016. (In Chinese)

[6] Andreas Hoecht,"Quality assurance in UK higher education:issues of trust,control, professional autonomy and accountability," Higher Education,vol.51, pp.556,2006.

[7] J.F. Perellon,'Path dependency and the politics of quality assurance in higher education,'Tertiary Education and Management,pp.279-280, Nov.2005.

[8] T. E. Shen, W.M. Guo, "From theory to action: iInterpretation of undergraduate teaching audit," Higher Education Development and Evaluation, Vol.30,pp.11-18, Apr. 2014. (In Chinese) 